\title{
Transmission of proteotoxicity across cellular compartments
}

\author{
Takunari Yoneda, Fumihiko Urano, and David Ron ${ }^{1}$ \\ Skirball Institute of Biomolecular Medicine, Departments of Medicine and Cell Biology, New York University School \\ of Medicine, New York, New York 10016, USA
}

An important subgroup of human neurodegenerative diseases is associated with abnormal expansions of glutamine repeats found in several otherwise unrelated proteins (Zoghbi and Orr 2000). Interest in these polyglutamine diseases is fueled both by their clinical significance and by the belief that lessons gleaned from these relatively rare conditions will apply to other more prevalent human neurodegenerative disorders and perhaps more generally to other diseases of aging. The basis for this belief is the observation that polyglutamine diseases and common neurodegenerative disorders, such as Alzheimer's disease and Parkinson's disease, share as a common feature the accumulation of abnormal protein aggregates in and around affected neurons (Kaytor and Warren 1999). In the polyglutamine diseases there is a good correlation between the length of the glutamine repeat, the tendency of the affected protein to assume abnormal aggregation-prone states of folding, and the occurrence of neurodegeneration (Gusella and MacDonald 2000; Orr 2001). Furthermore, there is reason to believe that despite the dissimilarities in structure and function of the proteins that "host" the glutamine repeat, once the polyglutamine expansion has reached a critical length, it imposes a common abnormal folding state on the affected protein (Perutz 1996). Together with the dominant inheritance pattern of the associated diseases, these observations suggest that the abnormal polyglutamine repeat converts host proteins into toxic entities, or proteotoxins (Hightower 1991). Attempts to understand the pathophysiology of polyglutamine diseases have therefore focused on the physical state of the abnormal protein, the cellular compartment in which it is found, and the impact of the abnormal protein on cell physiology. A paper in this issue of Genes \& Development reports on a pathogenic polyglutamine protein that accumulates as a nuclear aggregate yet triggers the unfolded protein response-a cellular response to unfolded and misfolded proteins in the endoplasmic reticulum (Nishitoh et al. 2002). We will discuss some of the implications of this finding whereby the impact of a polyglutamine-contain-

${ }^{1}$ Corresponding author.

E-MAIL ron@saturn.med.nyu.edu; FAX (212) 2638951.

Article and publication are at http://www.genesdev.org/cgi/doi/10.1101/ gad.1000902. ing proteotoxin can be transmitted from one cellular compartment to another.

\section{Components of polyglutamine proteotoxicity}

The pathogenicity of polyglutamine proteins is believed to have two components: a common component that is manifest by all such proteotoxins and a specific component that is dependent on the functions of each host protein. Evidence for the existence of a common component to polyglutamine proteotoxicity is provided by the observation that fragments of polyglutamine-expanded proteins in which much of the host protein's sequence had been removed are still able to recapitulate important aspects of human neurodegenerative disorders when expressed from transgenes at high levels in susceptible neurons (Ikeda et al. 1996; Mangiarini et al. 1996). In some cases these trimmed-down polyglutamine proteins were even more potent than the naturally-occurring human disease-causing proteins, leading some to suggest that the toxic principle elaborated in the human disease may be a processed form of the abnormal gene's primary translation product (DiFiglia et al. 1997).

Different processes are perturbed in polyglutamine-expressing cells, but distinguishing primary biochemical events common to all polyglutamine proteotoxins from distant downstream consequences of proteotoxicity remains a major challenge. One of the more coherent hypotheses pertains to the ability of polyglutamine proteins to perturb signaling by transcriptional regulators that have glutamine-rich tracts themselves. According to this theory, interactions between the glutamine stretches in the wild-type transcription factors and the polyglutamine proteotoxin sequester the former in inactive complexes (Shimohata et al. 2000). This mechanism may account for some of the toxicity associated with nuclear polyglutamine proteins (Paulson et al. 1997), but it is less successful in explaining the pathogenesis of disease caused by cytoplasmic polyglutamine proteins (Huynh et al. 2000).

One of the features common to polyglutamine proteotoxins is their tendency to aggregate. This is reflected in their behavior both in vitro and in living cells. Aggregation is believed to be due to the propensity of polyglutamine tracts to form pleated sheets of beta-strands held 
together by hydrogen bonds between their amides. This abnormal and highly stable structure may perturb the tertiary structure of the adjacent peptide chain (in cis) or invade other proteins (in trans), exposing side chains that are normally buried in the hydrophobic core of the protein (Perutz 1996). The resulting misfolded proteins may constitute a platform for combinatorial display of novel surface determinants that are not found in proteins that have folded properly. These novel misfolded conformations (that may also exist in other misfolding diseases) have never been subject to evolutionary selection. Therefore, the possibility for promiscuous interaction with cellular determinants and the resulting perturbation of cell physiology has never been selected against. Similar novel surface determinants likely emerge transiently in the course of normal protein folding, a context in which they are recognized by chaperones and prevented from undergoing illegitimate interactions with other cellular constituents (Bucciantini et al. 2002). Polyglutamine proteotoxins, too, are associated with cellular chaperones, and overexpression of chaperones can suppress the toxicity associated with polyglutamine proteins (Cummings et al. 1998; Chan et al. 2000; KazemiEsfarjani and Benzer 2000; Cummings et al. 2001). Together these findings suggest that cells treat polyglutamine proteins as unfolded proteins.

Eventually, proteins that fail to fold properly are targeted for degradation. Often an early step in this process is ubiquitination, a covalent modification that marks the protein for destruction and directs it to the proteasome, a machine for proteolytic degradation (Hershko and Ciechanover 1998). An alternative fate for some ubiquitinated and nonubiquitinated proteins is delivery to the aggresome, a cellular repository of abnormal proteins that have evaded degradation by one means or another (Kopito 2000). The polyglutamine protein aggregates found in degenerating neurons stain positive for ubiquitin and for components of the proteasomal machinery (Paulson et al. 1997; Cummings et al. 1998), suggesting that cells treat these proteins as abnormal entities earmarked for destruction or, failing that, for sequestration out of harm's way. Indeed, genetic manipulations that impede either proteasomal degradation of polyglutamine proteins or their incorporation into visible aggregates enhance their toxicity (Saudou et al. 1998; Cummings et al. 1999).

Polyglutamine proteins are not only substrates for the ubiquitin-proteasome system, they may also serve as competitive inhibitors of this important pathway of intracellular protein degradation. When expressed at high levels in HEK293 cells, a polyglutamine fragment of the Huntingtin protein interfered with proteasome-mediated degradation of a short-lived marker protein (Bence et al. 2001). Inhibition of the ubiquitin-proteasome system is not unique to polyglutamine proteins, as overexpression of a malfolding-prone mutant cystic fibrosis membrane conductance regulator $\left(\mathrm{CFTR}^{\Delta \mathrm{F} 508}\right)$ that is itself normally degraded by the ubiquitin-proteasome system, also inhibited this pathway and stabilized the shortlived marker protein (Bence et al. 2001). The ubiquitin- proteasome system degrades not only misfolded proteins but also many properly folded ones. The cell relies on the ubiquitin-proteasome system to eliminate key signaling molecules in a regulated fashion. For example, the transition between different phases of the cell cycle is effected by timely degradation of cyclins. Consequently, the inhibition of the ubiquitin-proteasome system by polyglutamine proteins affects not only the handling of these and other misfolded proteins, but also indirectly affects other important cellular processes (Bence et al. 2001).

\section{The unfolded protein response}

The endoplasmic reticulum (ER) is a major site of posttranslational protein processing. This is particularly true of neurons that must maintain long plasma membraneenclosed processes and an elaborate secretory apparatus. Equilibrium between the flux of client proteins entering the ER and the capacity of the organelle to handle its load is maintained by several signaling pathways, that together constitute a so-called unfolded protein response (UPR). The UPR is initiated in response to an imbalance between folding capacity and client protein load, a state of affairs heuristically referred to as ER stress. ER stress occurs in a variety of pathological states but it also accompanies physiological fluctuations in client protein load (Lee 1992; Kaufman 1999). The UPR has several known functional components. An early reduction in protein synthesis is mediated by the eukaryotic translation initiation factor-2 kinase, PERK (Harding et al. 1999|. This serves to rapidly reduce the load of client proteins entering the organelle. Failure to effect this response markedly reduces the resistance of cells even to physiological levels of ER stress (Harding et al. 2000, 2001; Scheuner et al. 2001).

The translational response to ER stress comes at the expense of completing the organelle's mission, which is to process secreted and membrane-bound client proteins. Therefore, cells have elaborated a second phase of the UPR that increases the ER's capacity to process client proteins. This later phase consists of transcriptional activation of genes whose products play a role in all aspects of posttranslational protein processing in the secretory pathway (for review, see Patil and Walter 2001). The mRNAs induced by the UPR encode, among others, ER chaperones, disulfide exchange factors, oxidoreductases, proteins involved in vesicular transport from the ER, and, notably, many components of the ER-associated protein degradation (ERAD) machinery. The latter consists of a cellular apparatus that recognizes unfolded and misfolded proteins in the lumen of the ER and on its membranes, delivers them through the translocon pore in a process referred to as retrotranslocation, and ensures their ultimate destruction on the cytoplasmic side by the proteasome (for reviews, see Sommer and Wolf 1997; Plemper and Wolf 1999). Genetic studies in yeast have revealed the functional importance of up-regulating the ERAD apparatus to the resistance of cells to ER stress, indicating that it is tightly integrated into the UPR 
(Casagrande et al. 2000; $\mathrm{Ng}$ et al. 2000; Travers et al. 2000).

Two of the three known upstream activators of the mammalian UPR share a common mechanism of activation. PERK and IRE1 are type-1 transmembrane ERresident proteins with a functionally interchangeable lumenal domain that responds to ER stress signals and a cytoplasmic effector protein kinase domain that initiates downstream signaling. Activation of PERK and IRE1 correlates with their oligomerization in the plane of the ER membrane, an event that precedes trans-autophosphorylation and activation of downstream signaling (Bertolotti et al. 2000; Liu et al. 2000; Okamura et al. 2000). The lumenal domains of PERK and IRE1 are recognized by the lumenal chaperone $\mathrm{BiP}$, and $\mathrm{BiP}$ binding inhibits the oligomerization event that initiates signaling in the UPR (Bertolotti et al. 2000; Okamura et al. 2000; Liu et al. 2002). These observations are consistent with a model whereby cells seek to defend a certain level of dispensable BiP in their ER. During ER stress, client proteins titrate BiP away from the lumenal domains of PERK and IRE1, thereby activating the UPR. As translation levels fall, and later as ER chaperone levels increase and ERAD components are up-regulated, the level of unfolded and misfolded client proteins diminishes and dispensable $\mathrm{BiP}$ is once again available to inhibit PERK and IRE1. This model for the UPR setpoint implies that even a small surplus of unfolded ER client proteins beyond the buffering capacity of the ER chaperones is disadvantageous. Perhaps in the ER, too, combinatorial display of hydrophobic side chains exposed on normal folding intermediates and on misfolded proteins must be masked by chaperones to avoid creation of novel proteotoxins.

\section{Polyglutamine proteins, ER stress, and programmed cell death}

In this issue of Genes \& Development, Nishitoh and colleagues report that the expression of a pathogenic polyglutamine-containing fragment from the SCA3 protein implicated in Machado-Joseph Disease (SCA3-Q79) in rat pheochromocytoma PC12 cells leads to marked activation of IRE1 and PERK. PERK and IRE1 are specifically activated by ER lumenal signal(s) and not by stress signals emanating from other cellular compartments (Tirasophon et al. 1998; Harding et al. 1999; Bertolotti et al. 2000), suggesting that their activation is specific for ER stress. A possible solution to the mystery of how SCA3Q79 (which is not translocated to the ER lumen) induces ER stress was provided by the observation that SCA3Q79 inhibits proteasome function and that treatment of PC12 cells with a proteasome inhibitor likewise activates PERK and IRE1. These findings are consistent with a chain of events whereby SCA3-Q79 engages and inhibits the ubiquitin-proteasome system (as predicted by Bence et al. 2001). Because the ubiquitin-proteasome system is also involved in degradation of misfolded ER proteins, the secondary ER-associated protein degradation defect induced by SCA3-Q79 initiates ER stress that is reflected in IRE1 and PERK activation (Nishitoh et al. 2002).

SCA3-Q79 is highly toxic; when it is expressed from a transgene in either cultured cells or in vivo in neurons, the protein causes cell death and neurological dysfunction (Ikeda et al. 1996; Paulson et al. 1997). To address the potential role of ER stress in mediating these effects of SCA3-Q79, Nishitoh and colleagues examined downstream signaling in the UPR. They discovered links between ER stress caused by SCA3-Q79 and activation of JUN N-terminal kinases (JNKs), stress-induced protein kinases implicated in programmed cell death (for review, see Davis 1999). To evaluate the significance of these findings we need to briefly review the connection between ER stress and programmed cell death.

Exposure of cells to toxins that perturb protein folding in the ER eventually leads to cell death. This is hardly surprising, if one considers the many cellular processes that depend on the integrity of the ER's protein processing machinery (consider, for example, that most cell surface receptors implicated in receiving survival signals are folded and processed in the ER). However, recently accrued evidence points to the existence of specific deathpromoting pathways that are activated during ER stress. The first of these to be identified is downstream from the transcription factor CHOP (or GADD153), a small bZIP protein that is activated transcriptionally and posttranscriptionally by ER stress. $\mathrm{CHOP}^{-/-}$cells and animals are partially resistant to ER stress (Zinszner et al. 1998; McCullough et al. 2001; Oyadomari et al. 2002) and ectopic expression of CHOP promotes cell death (Friedman 1996; McCullough et al. 2001). Interestingly, CHOP induction by ER stress requires signaling downstream of PERK, in a cascade that involves phosphorylation of eukaryotic translation initiation factor-2 and translational induction of ATF4, a transcription factor upstream of CHOP (Harding et al. 2000; Scheuner et al. 2001). Therefore, certain aspects of PERK signaling promote survival in ER stress while others promote cell death. It is plausible that PERK contributes to cell survival at moderate levels of ER stress and to cell death at higher levels.

Another death-promoting pathway that is activated during ER stress is mediated by an ER-localized caspase, Caspase-12. Caspase-12 is activated specifically by ER stress and contributes to programmed cell death during ER stress, as CASP12-/- cells are resistant to ER stress but not to other death-promoting perturbations (Nakagawa et al. 2000). The pathways linking ER stress to caspase-12 activation have yet to be worked out in detail, but elevated cytoplasmic calcium levels (which may accompany cellular conditions that cause ER stress) play a role in proteolytic processing of caspase-12 by calpain (Nakagawa and Yuan 2000). More directly related to ER stress is the observation that IRE1 recruits and clusters caspase-12 at the ER membrane in stressed cells, leading to its activation (Yoneda et al. 2001). This last mechanism is relevant to findings reported on by Nishitoh and colleagues in this issue because it reveals an unexpected aspect of mammalian IRE1 activity-a diversity of downstream effectors. 
IRE1 was first identified in yeast, where it is required for all gene activation in the UPR /Casagrande et al. 2000; Travers et al. 2000). Signaling downstream from IRE1 entails the endonucleolytic processing of the HAC1 mRNA. In ER-stressed yeast, Irelp undergoes trans-autophosphorylation, which activates its effector function-the precise cleavage of the HAC1 mRNA. The unprocessed form of HAC1 mRNA, present in unstressed cells, is poorly translated, whereas the processed mRNA is efficiently translated into a transcription factor, Haclp, that binds and activates target genes of the yeast UPR (Mori 2000; Patil and Walter 2001). Mammalian cells also have IRE1 proteins and recently a HAC1like mRNA (transcribed from the XBP-1 gene) was found to signal downstream from IRE1 in the mammalian UPR (Shen et al. 2001; Yoshida et al. 2001; Calfon et al. 2002). The role of the mammalian IRE1 and XBP-1 signaling pathway has not been fully elucidated, however there is reason to believe that it may be implicated in promoting increased ER client protein processing capacity.

In addition to signaling as a site-specific endoribonuclease in the evolutionarily-conserved signaling pathway described above, mammalian IRE1 proteins have also acquired the ability to engage in parallel signaling. Activated and phosphorylated mammalian IRE1 proteins bind to the cytoplasmic adaptor protein TRAF2 and recruit it to ER membranes, resulting in JNK activation. This pathway is likely to be relevant to JNK activation by ER stress, as IRE1 knockout cells are impaired in JNK activation specifically by ER stress and dominant-negative TRAF2 interferes in signaling from IRE1 to JNK (Urano et al. 2000b). The functional significance of this signaling pathway has not been established, though it was deemed possible that JNK activation mediates some of the death-promoting effects of IRE1, as noted in earlier studies (Wang et al. 1998).

Nishitoh and colleagues extend these observations in important ways. First, they found that the upstream kinase ASK1, a MAPKKK previously implicated in cell death under a variety of conditions (for review, see Matsuzawa and Ichijo 2001), is required for linking the IRE1TRAF2 complex to JNK activation, as $A S K 1^{-1-}$ mouse fibroblasts fail to activate JNKs in response to IRE1 activation. This finding was expected, as the same group has squarely placed ASK1 downstream from TRAF2 in other signaling cascades that activate JNK (Nishitoh et al. 1998). The ASK1 mutation also interfered with JNK activation by proteasomal inhibitors or by other agents that promote ER stress or by SCA3-Q79 expression. Most importantly, the $A S K 1^{-/-}$fibroblasts and primary neurons were resistant to cell death induced by proteasomal inhibitors or other agents that cause ER stress and to the death-promoting effects of SCA3-Q79. These compelling experiments support a model whereby the signaling pathway linking ER stress, IRE1, TRAF2, ASK1 and JNK has an important role in promoting cell death by polyglutamine-containing proteotoxins.

Several caveats apply to interpreting these interesting results. First, it is not proven that ASK1's role in promoting cell death in the SCA3-Q79-expressing cells is initiated by ER stress. Though the study conclusively shows that ASK1 is required for JNK activation and cell death by ER stress, it remains possible that another stress pathway that is also activated by polyglutaminecontaining proteotoxins mediates ASK1-dependent cell death. In principle one could address this issue by examining the impact of IRE1 deletion on neuronal death caused by polyglutamine-containing proteotoxins. However, there are conceptual and technical difficulties in addressing this question experimentally. There are two IRE1 genes in mammals and the isoform expressed in neurons, IRE $1 \alpha$, is essential for embryonic development (Urano et al. 2000a; Lee et al. 2002). Therefore, procuring cultured neurons that are null for IRE1 $\alpha$ may not be trivial. Secondly, given what we know about the UPR it seems likely that the IRE1 pathway (like the PERK signaling pathway) may exert opposing influences on cell survival during ER stress. Signaling through XBP-1 would increase ER capacity and protect cells from ER stress whereas signaling through TRAF2 would promote cell death by activating JNK. The experiment is therefore unlikely to be conclusive.

It is also important to recognize that these studies attempt to recapitulate a pathophysiological process that is played out over many years in neurons of affected humans in several days in a tissue culture plate. To achieve this, the polyglutamine proteotoxin is expressed at high levels. This is an important concern, as the phenomena uncovered by Nishitoh and colleagues are best explained by inhibition of the ubiquitin-proteasome system, which might be highly dependent on the level at which the proteotoxin is expressed. It is therefore possible that inhibition of the ubiquitin-proteasome system is important in the experimental system used by Nishitoh and colleagues, but has little impact in clinical polyglutamine disease. This potential problem may have been compounded by reliance on cell death as a phenotypic readout. While neuronal cell death clearly occurs in polyglutamine diseases, it is often preceded by organ dysfunction. This is true both in clinical disease and in some of the experimental mouse models (for review, see Orr 2001). Therefore, it is possible that the IRE1 to JNK signaling cascade is implicated in neuronal death caused by polyglutamine containing proteotoxins without playing a major role in the pathophysiology of the human polyglutamine diseases.

There are several ways to begin to address the last concern. One might try to construct transgenic models for polyglutamine disease, such as the SCA3-Q79 transgene (described by Ikeda et al. 1996), in the $A S K 1^{-/-}$ mice. More generally, as both CASP12-/- and $\mathrm{CHOP}^{-/-}$ mice are ostensibly normal, it is possible to examine the impact of mutations in these effectors of ER stress-mediated cell death on the phenotype of established transgenic models of polyglutamine disease. If ER stress-mediated cell death were important to the development of disease in these mouse models, one would expect an attenuated phenotype in the CASP $12^{-/-}$and $\mathrm{CHOP}^{-/-} \mathrm{mu}-$ tant mice.

An additional question raised by these studies is the 
nature of the link between polyglutamine proteotoxins, the defects in the ubiquitin-proteasome system and ERassociated protein degradation, and the development of ER stress. A target for inhibition by polyglutamine proteins that might be implicated in this process is a complex containing the AAA ATPase, VCP/p97/CDC48, which promotes ER-associated protein degradation (Ye et al. 2001; Jarosch et al. 2002). A recent study found that the $\mathrm{VCP} / \mathrm{p} 97 / \mathrm{CDC} 48$-containing complex interacts physically with polyglutamine proteotoxins and that expression of dominant negative forms of $\mathrm{VCP} / \mathrm{p} 97 /$ CDC48 led to cell death with features resembling those induced by polyglutamine proteotoxins (Hirabayashi et al. 2001). Interpreting these results is complicated by observations made by the same group whereby loss of ter 94 (Drosophila VCP/p97/CDC48) suppresses polyglutamine proteotoxicity in the Drosophila eye (Higashiyama et al. 2002). The latter suggest that rather than being inhibited by polyglutamine proteotoxicity, the VCP/ p97/CDC48-containing complex is its effector. It would be interesting nonetheless to examine the impact of mutations in the IRE1, TRAF2, ASK1, and JNK pathway on the phenotypes associated with perturbed $\mathrm{VCP} / \mathrm{p} 97 /$ CDC48 function.

In summary, the study by Nishitoh and colleagues in this issue and the earlier study by Bence and colleagues (Bence et al. 2001) call attention to the potential for misfolded proteins to inhibit intracellular protein degradation and perhaps to saturate chaperone reserve in the ER. These studies nicely show how this mechanism might account for the transmission of proteotoxicity's impact across cellular compartments, recruiting pathogenic cascades at a distance from the primary inciting proteotoxin. Many neurodegenerative diseases share as a common feature the production and accumulation of abnormal misfolded proteins, therefore the phenomena revealed in the studies described above may have general relevance to neurodegeneration.

\section{Acknowledgments}

We are indebted to Moses Chao, Harry Orr, and Ron Kopito for comments on this manuscript. Work in our lab is supported by NIH grants DK47119, ES08681 and NS436281. DR is an Ellison Foundation Senior Scholar on Aging.

\section{References}

Bence, N.F., Sampat, R.M., and Kopito, R.R. 2001. Impairment of the ubiquitin-proteasome system by protein aggregation. Science 292: 1552-1555.

Bertolotti, A., Zhang, Y., Hendershot, L., Harding, H., and Ron, D. 2000. Dynamic interaction of $\mathrm{BiP}$ and the ER stress transducers in the unfolded protein response. Nat. Cell Biol. 2: 326-332.

Bucciantini, M., Giannoni, E., Chiti, F., Baroni, F., Formigli, L., Zurdo, J., Taddei, N., Ramponi, G., Dobson, C.M., and Stefani, M. 2002. Inherent toxicity of aggregates implies a common mechanism for protein misfolding diseases. Nature 416: $507-511$.

Calfon, M., Zeng, H., Urano, F., Till, J.H., Hubbard, S.R., Har- ding, H.P., Clark, S.G., and Ron, D. 2002. IRE1 couples endoplasmic reticulum load to secretory capacity by processing the XBP-1 mRNA. Nature 415: 92-96.

Casagrande, R., Stern, P., Diehn, M., Shamu, C., Osario, M., Zuniga, M., Brown, P.O., and Ploegh, H. 2000. Degradation of proteins from the ER of $S$. cerevisiae requires an intact unfolded protein response pathway. Mol. Cell 5: 729-735.

Chan, H.Y., Warrick, J.M., Gray-Board, G.L., Paulson, H.L., and Bonini, N.M. 2000. Mechanisms of chaperone suppression of polyglutamine disease: selectivity, synergy and modulation of protein solubility in Drosophila. Hum. Mol. Genet. 9: 2811-2820.

Cummings, C.J., Mancini, M.A., Antalffy, B., DeFranco, D.B., Orr, H.T., and Zoghbi, H.Y. 1998. Chaperone suppression of aggregation and altered subcellular proteasome localization imply protein misfolding in SCA1. Nat. Genet. 19: 148-154.

Cummings, C.J., Reinstein, E., Sun, Y., Antalffy, B., Jiang, Y., Ciechanover, A., Orr, H.T., Beaudet, A.L., and Zoghbi, H.Y. 1999. Mutation of the E6-AP ubiquitin ligase reduces nuclear inclusion frequency while accelerating polyglutamine-induced pathology in SCA1 mice. Neuron 24: 879-892.

Cummings, C.J., Sun, Y., Opal, P., Antalffy, B., Mestril, R., Orr, H.T., Dillmann, W.H., and Zoghbi, H.Y. 2001. Over-expression of inducible HSP70 chaperone suppresses neuropathology and improves motor function in SCA1 mice. Hum. Mol. Genet. 10: 1511-1518.

Davis, R.J. 1999. Signal transduction by the c-Jun N-terminal kinase. Biochem. Soc. Symp. 64: 1-12.

DiFiglia, M., Sapp, E., Chase, K.O., Davies, S.W., Bates, G.P., Vonsattel, J.P., and Aronin, N. 1997. Aggregation of huntingtin in neuronal intranuclear inclusions and dystrophic neurites in brain. Science 277: 1990-1993.

Friedman, A.D. 1996. GADD153/CHOP, a DNA damage-inducible protein, reduced CAAT/enhancer binding protein activities and increased apoptosis in 32D c13 myeloid cells. Cancer Res. 56: 3250-3256.

Gusella, J.F. and MacDonald, M.E. 2000. Molecular genetics: unmasking polyglutamine triggers in neurodegenerative disease. Nat. Rev. Neurosci. 1: 109-115.

Harding, H., Zhang, Y., and Ron, D. 1999. Translation and protein folding are coupled by an endoplasmic reticulum resident kinase. Nature 397: 271-274.

Harding, H., Zhang, Y., Bertolotti, A., Zeng, H., and Ron, D 2000. Perk is essential for translational regulation and cell survival during the unfolded protein response. Mol. Cell. 5: 897-904.

Harding, H., Zeng, H., Zhang, Y., Jungreis, R., Chung, P., Plesken, H., Sabatini, D., and Ron, D. 2001. Diabetes Mellitus and excocrine pancreatic dysfunction in Perk ${ }^{-/-}$mice reveals a role for translational control in survival of secretory cells. Mol. Cell. 7: 1153-1163.

Hershko, A. and Ciechanover, A. 1998. The ubiquitin system. Annu. Rev. Biochem. 67: 425-479.

Higashiyama, H., Hirose, F., Yamaguchi, M., Inoue, Y.H., Fujikake, N., Matsukage, A., and Kakizuka, A. 2002. Identification of ter94, Drosophila VCP, as a modulator of polyglutamine-induced neurodegeneration. Cell Death Differ. 9: 264273.

Hightower, L.E. 1991. Heat shock, stress proteins, chaperones, and proteotoxicity. Cell 66: 191-197.

Hirabayashi, M., Inoue, K., Tanaka, K., Nakadate, K., Ohsawa, Y., Kamei, Y., Popiel, A.H., Sinohara, A., Iwamatsu, A., Kimura, Y., et al. 2001. VCP/p97 in abnormal protein aggregates, cytoplasmic vacuoles, and cell death, phenotypes relevant to neurodegeneration. Cell Death Differ. 8: 977-984.

Huynh, D.P., Figueroa, K., Hoang, N., and Pulst, S.M. 2000 
Nuclear localization or inclusion body formation of ataxin-2 are not necessary for SCA2 pathogenesis in mouse or human. Nat. Genet. 26: 44-50.

Ikeda, H., Yamaguchi, M., Sugai, S., Aze, Y., Narumiya, S., and Kakizuka, A. 1996. Expanded polyglutamine in the Machado-Joseph disease protein induces cell death in vitro and in vivo. Nat. Genet. 13: 196-202.

Jarosch, E., Taxis, C., Volkwein, C., Bordallo, J., Finley, D., Wolf, D.H., and Sommer, T. 2002. Protein dislocation from the ER requires polyubiquitination and the AAA- ATPase Cdc48. Nat. Cell Biol. 4: 134-139.

Kaufman, R.J. 1999. Stress signaling from the lumen of the endoplasmic reticulum: coordination of gene transcriptional and translational controls. Genes \& Dev. 13: 1211-1233.

Kaytor, M.D. and Warren, S.T. 1999. Aberrant protein deposition and neurological disease. J. Biol. Chem. 274: 37507-37510.

Kazemi-Esfarjani, P. and Benzer, S. 2000. Genetic suppression of polyglutamine toxicity in Drosophila. Science 287: 1837-1840.

Kopito, R.R. 2000. Aggresomes, inclusion bodies and protein aggregation. Trends Cell. Biol. 10: 524-530.

Lee, A.S. 1992. Mammalian stress response: induction of the glucose-regulated protein family. Curr. Opin. Cell Biol. 4: $267-273$

Lee, K., Tirasophon, W., Shen, X., Michalak, M., Prywes, R., Okada, T., Yoshida, H., Mori, K., and Kaufman, R.J. 2002. IRE1-mediated unconventional mRNA splicing and S2P-mediated ATF6 cleavage merge to regulate XBP1 in signaling the unfolded protein response. Genes \& Dev. 16: 452-466.

Liu, C.Y., Schroder, M., and Kaufman, R.J. 2000. Ligand-independent dimerization activates the stress-response kinases IRE1 and PERK in the lumen of the endoplasmic reticulum. J. Biol. Chem. 275: 24881-24885.

Liu, C.Y., Wong, H.N., Schauerte, J.A., and Kaufman, R.J. 2002. The protein kinase/endoribonuclease IRE1a that signals the unfolded protein response has a lumenal amino-terminal ligand-independent dimerization domain. J. Biol. Chem. March 15: [e-pub ahead of print].

Mangiarini, L., Sathasivam, K., Seller, M., Cozens, B., Harper, A., Hetherington, C., Lawton, M., Trottier, Y., Lehrach, H., Davies, S.W., et al. 1996. Exon 1 of the HD gene with an expanded CAG repeat is sufficient to cause a progressive neurological phenotype in transgenic mice. Cell 87: 493-506.

Matsuzawa, A. and Ichijo, H. 2001. Molecular mechanisms of the decision between life and death: regulation of apoptosis by apoptosis signal-regulating kinase 1. J. Biochem. 130: 1-8.

McCullough, K.D., Martindale, J.L., Klotz, L.O., Aw, T.Y., and Holbrook, N.J. 2001. Gadd153 sensitizes cells to endoplasmic reticulum stress by down- regulating Bcl2 and perturbing the cellular redox state. Mol. Cell. Biol. 21: 1249-1259.

Mori, K. 2000. Tripartite management of unfolded proteins in the endoplasmic reticulum. Cell 101: 451-454.

Nakagawa, T. and Yuan, J. 2000. Cross-talk between two cysteine protease families: Activation of caspase-12 by calpain in apoptosis. J. Cell Biol. 150: 887-894.

Nakagawa, T., Zhu, H., Morishima, N., Li, E., Xu, J., Yankner, B.A., and Yuan, J. 2000. Caspase-12 mediates endoplasmic reticulum-specific apoptosis and cytotoxicity by amyloid- $\beta$. Nature 403: 98-103.

Ng, D.T., Spear, E.D., and Walter, P. 2000. The unfolded protein response regulates multiple aspects of secretory and membrane protein biogenesis and endoplasmic reticulum quality control. J. Cell Biol. 150: 77-88.

Nishitoh, H., Saitoh, M., Mochida, Y., Takeda, K., Nakano, H., Rothe, M., Miyazono, K., and Ichijo, H. 1998. ASK1 is essen- tial for JNK/SAPK activation by TRAF2. Mol. Cell 2: 389395.

Nishitoh, H., Matsuzawa, A., Tobiume, K., Saegusa, K., Takeda K., Inoue, K., Hori, S., Ishikawa, K., Mizusawa, H., Kakizuka, A., and Ichijo, H. 2002. ASK1 is essential for endoplasmic reticulum stress-induced neuronal cell death triggered by expanded polyglutamine repeats. Genes \& Dev. 16: 1345-1355.

Okamura, K., Kimata, Y., Higashio, H., Tsuru, A., and Kohno, K. 2000. Dissociation of Kar2p/BiP from an ER sensory molecule, Irelp, triggers the unfolded protein response in yeast. Biochem. Biophys. Res. Commun. 279: 445-450.

Orr, H.T. 2001. Beyond the Qs in the polyglutamine diseases. Genes \& Dev. 15: 925-932.

Oyadomari, S., Koizumi, A., Takeda, K., Gotoh, T., Akira, S., Araki, E., and Mori, M. 2002. Targeted disruption of the Chop gene delays endoplasmic reticulum stress-mediated diabetes. J. Clin. Invest. 109: 525-532.

Patil, C. and Walter, P. 2001. Intracellular signaling from the endoplasmic reticulum to the nucleus: the unfolded protein response in yeast and mammals. Curr. Opin. Cell Biol. 13: 349-355.

Paulson, H.L., Perez, M.K., Trottier, Y., Trojanowski, J.Q., Subramony, S.H., Das, S.S., Vig, P., Mandel, J.L., Fischbeck, K.H., and Pittman, R.N. 1997. Intranuclear inclusions of expanded polyglutamine protein in spinocerebellar ataxia type 3. Neuron 19: 333-344.

Perutz, M.F. 1996. Glutamine repeats and inherited neurodegenerative diseases: molecular aspects. Curr. Opin. Struct. Biol. 6: 848-858.

Plemper, R.K. and Wolf, D.H. 1999. Retrograde protein translocation: ERADication of secretory proteins in health and disease. Trends Biochem. Sci. 24: 266-270.

Saudou, F., Finkbeiner, S., Devys, D., and Greenberg, M.E. 1998 Huntingtin acts in the nucleus to induce apoptosis but death does not correlate with the formation of intranuclear inclusions. Cell 95: 55-66.

Scheuner, D., Song, B., McEwen, E., Gillespie, P., Saunders, T., Bonner-Weir, S., and Kaufman, R.J. 2001. Translational control is required for the unfolded protein response and in vivo glucose homeostasis. Mol. Cell 7: 1165-1176.

Shen, X., Ellis, R.E., Lee, K., Liu, C.-Y., Yang, K., Solomon, A., Yoshida, H., Morimoto, R., Kurnit, D.M., Mori, K., and Kaufman, R.J. 2001. Complementary signaling pathways regulate the unfolded protein response and are required for C. elegans development. Cell 107: 893-903.

Shimohata, T., Onodera, O., and Tsuji, S. 2000. Interaction of expanded polyglutamine stretches with nuclear transcription factors leads to aberrant transcriptional regulation in polyglutamine diseases. Neuropathol. 20: 326-333.

Sommer, T. and Wolf, D.H. 1997. Endoplasmic reticulum degradation: reverse protein flow of no return. Faseb J. 11: 12271233.

Tirasophon, W., Welihinda, A.A., and Kaufman, R.J. 1998. A stress response pathway from the endoplasmic reticulum to the nucleus requires a novel bifunctional protein kinase/ endoribonuclease (Irelp) in mammalian cells. Genes \& Dev. 12: $1812-1824$.

Travers, K.J., Patil, C.K., Wodicka, L., Lockhart, D.J., Weissman, J.S., and Walter, P. 2000. Functional and genomic analyses reveal an essential coordination between the unfolded protein response and ER-associated degradation. Cell 101: 249258.

Urano, F., Bertolotti, A., and Ron, D. 2000a. IRE1 and efferent signaling from the endoplasmic reticulum. I. Cell Sci. 113: 3697-3702.

Urano, F., Wang, X., Bertolotti, A., Zhang, Y., Chung, P., Hard- 
ing, H., and Ron, D. 2000b. Coupling of Stress in the Endoplasmic Reticulum to Activation of JNK Protein Kinases by Transmembrane Protein Kinase IRE1. Science 287: 664-666.

Wang, X.Z., Harding, H.P., Zhang, Y., Jolicoeur, E.M., Kuroda, M., and Ron, D. 1998. Cloning of mammalian Ire1 reveals diversity in the ER stress responses. EMBO J. 17: 5708-5717.

Ye, Y., Meyer, H.H., and Rapoport, T.A. 2001. The AAA ATPase Cdc48/p97 and its partners transport proteins from the ER into the cytosol. Nature 414: 652-656.

Yoneda, T., Imaizumi, K., Oono, K., Yui, D., Gomi, F., Katayama, T., and Tohyama, M. 2001. Activation of caspase-12, an endoplastic reticulum (ER) resident caspase, through tumor necrosis factor receptor-associated factor 2-dependent mechanism in response to the ER stress. J. Biol. Chem. 276: 13935-13940.

Yoshida, H., Matsui, T., Yamamoto, A., Okada, T., and Mori, K. 2001. XBP1 mRNA is induced by ATF6 and spliced by IRE1 in response to ER stress to produce a highly active transcription factor. Cell 107: 881-891.

Zinszner, H., Kuroda, M., Wang, X., Batchvarova, N., Lightfoot, R.T., Remotti, H., Stevens, J.L., and Ron, D. 1998. CHOP is implicated in programmed cell death in response to impaired function of the endoplasmic reticulum. Genes \& Dev. 12: 982-995.

Zoghbi, H.Y. and Orr, H.T. 2000. Glutamine repeats and neurodegeneration. Annu. Rev. Neurosci. 23: 217-247. 


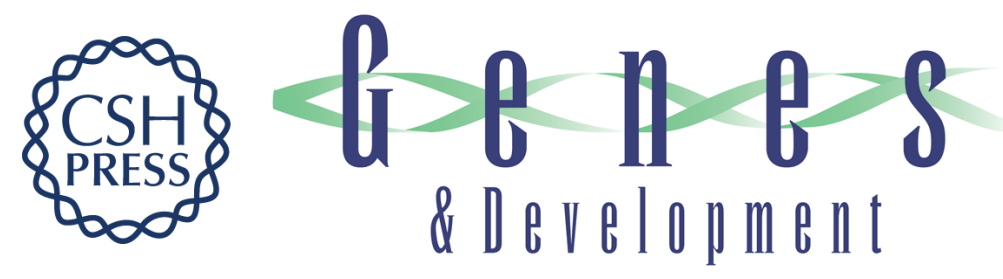

\section{Transmission of proteotoxicity across cellular compartments}

Takunari Yoneda, Fumihiko Urano and David Ron

Genes Dev. 2002, 16:

Access the most recent version at doi:10.1101/gad.1000902

References This article cites 60 articles, 19 of which can be accessed free at: http://genesdev.cshlp.org/content/16/11/1307.full.html\#ref-list-1

License

Email Alerting Receive free email alerts when new articles cite this article - sign up in the box at the top Service right corner of the article or click here.

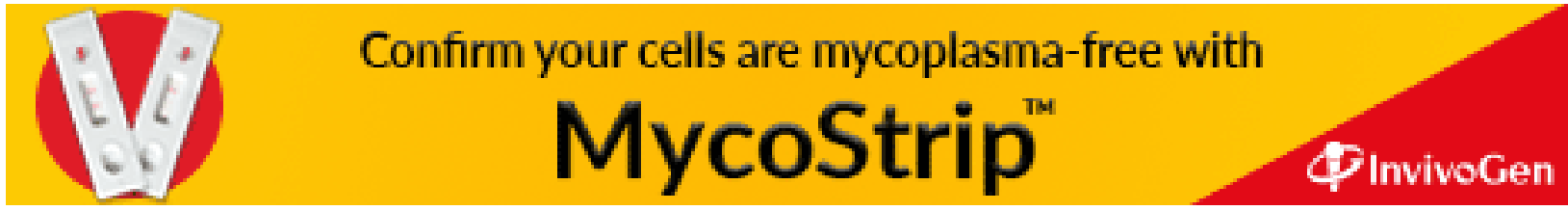

